\title{
Knowledge of Grammar and Concept Possession
}

\section{Edison Barrios}

\begin{abstract}
This paper deals with the cognitive relationship between a speaker and her internal grammar. In particular, it takes issue with the view that such a relationship is one of belief or knowledge (I call this view the 'Propositional Attitude View', or PAV). I first argue that PAV entails that all ordinary speakers (tacitly) possess technical concepts belonging to syntactic theory, and second, that most ordinary speakers do not in fact possess such concepts. Thus, it is concluded that speakers do not literally 'know' or 'believe' much of the contents of their grammars, and moreover, that these contents can only be attributed at a subpersonal level.
\end{abstract}

\section{The Propositional Attitude View (PAV) of Linguistic Competence}

How do speakers manage to be competent at speaking and understanding their native languages? How is it possible for linguists to obtain evidence from them, in the form of linguistic judgments? If we are to believe contemporary linguistics, ${ }^{1}$ any answer to these questions must relate speakers to their grammars, where a grammar is understood as a cognitive structure instantiated by an individual speaker. $^{2}$

But how is the speaker related to such a grammar so that she can exploit it in the course of language use and linguistic judgment? The characteristics of human linguistic competence strongly suggest that speakers stand in some sort of cognitive relation R to their grammars (see Chomsky [1986]; Isac and Reiss [2008]). The question is: how can we further characterize R? One appealing answer is that $\mathrm{R}$ constitutes a kind of propositional attitude, such as belief or knowledge. This seems to vindicate everyday talk of people 'knowing English (German/Tagalog,

\footnotetext{
${ }^{1}$ Although the term 'linguistics' designates a broad range of scientific activities, in this paper I will deal exclusively with theories in syntax, which is the most representative area of the Chomskyan school of linguistics, even though (or precisely because) philosophers have traditionally paid considerable less attention to syntax than to other areas of linguistic inquiry, such as semantics and pragmatics. Also, for stylistic reasons, I will frequently use the term 'Generative Grammar', or simply 'linguistics', to designate the research program in which I am interested. In doing so (and unless otherwise noted), I will be referring to Chomskyan, Generative Transformational syntax, and, in particular, to theories within the Principles and Parameters approach (see Chomsky, [1986]).

2 This mental structure is frequently referred to as 'I-language', as opposed to 'E-language', where the letter 'I' is supposed to highlight that this structure: (a) belongs to an individual, not a collective or community, (b) is internal to the subject, a part of her mind/brain, not some independent external entity that the speaker more or less imperfectly grasps, and last (c) is intensional: the grammar is intended to be the characterization in intension of a function that maps sounds and meanings, not some extensionally characterized set of sentences, utterances or inscriptions (see Chomsky, [1986] ch. 2).
} 
etc.)', while also providing an account of the informativeness of linguistic judgments (Graves et al, [1973]; Dwyer and Pietroski [1996]; Higginbotham [1987]) as well as of the distinction between linguistic competence and performance (Dwyer and Pietroski, [1996]; Knowles [2000]). ${ }^{3}$

Let us call this position the 'Propositional Attitude View' of linguistic competence (PAV). ${ }^{4}$

According to PAV, speakers are able to use and reflect on their languages partly by virtue of knowing or believing the grammatical principles or rules of their grammars, such as those described (or postulated) by linguistic theory. This enabling knowledge, as PAV authors are quick to point out, is not of the typical, explicit sort, such as our knowledge that $1+2=3$ or that Alberto Contador won the 2009 Tour de France. Rather, it is a kind of implicit or tacit knowledge, that is, knowledge that is unavailable to conscious reflection, even though it is exploited in language-related cognition. ${ }^{5}$

PAV has intuitive appeal and is not devoid of explanatory potential. But for all its initial attractiveness it brings along perplexities that threaten its plausibility. For instance, a cursory glance at a linguistics journal, or even at a textbook in the Principles and Parameters tradition, reveals

${ }^{3}$ For instance, one way of characterizing the distinction between competence and performance is by saying that the former is the (tacit) knowledge a speaker has of her grammar, whereas the latter is the manifestation of that knowledge in the course of language use. Linguistics, then, studies the first, not the second.

Likewise, one possible strategy for justifying the use of intuitions/judgments as evidence about competence is by arguing that they are reliable manifestations of the speaker's grammatical knowledge or beliefs.

${ }^{4}$ Dwyer and Pietroski ([1996]); Graves et al ([1973]); Higginbotham ([1987]) and Knowles ([2000]), among others, support PAV in one way or another with respect to grammar (for a similar view with respect to semantics, see Lepore ([1986]); Larson and Segal ([1995])). For instance, Dwyer and Pietroski ([1996], p. 338, emphasis mine), propose that generalizations of linguistic theory 'serve to ascribe beliefs to humans', whereas Knowles' thesis is that 'knowledge of grammatical principles may be seen as what philosophers call a variety of propositional attitude' (Knowles ([2000] p. 326), emphasis in the original), moreover, he attributes this view to Chomsky. George ([1990], p. 91) claims that the grammar of a speaker is 'the object of that speaker's knowledge'. The analogy with knowledge of numbers that he offers later in the text makes it quite plausible to assume that what he means by 'knowledge' is a propositional attitude.

Likewise, for Larson and Segal ([1995], p.10, italics mine) '[...] to view the subject matter of semantics as linguistic knowledge is to locate semantic theory within the general enterprise initiated by Noam Chomsky ([1965], [1975], [1986a]), for whom linguistic theory is a theory of the real knowledge of speakers'.

Fodor ([1983], p. 7) quite confidently attributes to Chomsky a view that is very close to PAV, if not PAV itself:

[...] when Chomsky says that there is an innately specified 'language organ' what he means is that $[\ldots]$ there are innately specified propositional contents $[\ldots$ and that ...] the ontogeny of linguistic capacities is the unfolding of the deductive consequences of the innate beliefs in interaction with perceptual data' (Fodor [1983], italics mine).

Whether Fodor's is a faithful characterization of Chomsky's position is another issue, but it certainly is a sign of the appeal of PAV.

This paper is not concerned with the particular views that each PAV author holds, but rather on what they share, which is a basic commitment to PAV.

5 The terms 'tacit' or 'implicit' are widely used in the philosophy of mind and cognitive science literature, frequently with different meanings. However, I will assume the following notion: a content $\mathrm{C}$ is explicit if it is accessible to consciousness, implicit otherwise. How would such a conscious accessibility manifest itself? C will be explicit to the extent that the subject can report, verbalize or reflect on propositions containing $\mathrm{C}$. This is the way in which 'tacit' is usually employed in cognitive psychology, for instance, in the study of memory and learning. See Davies ([2001]); Schacter ([1996]). 
grammatical generalizations and descriptions of sentence structure that involve specialized, technical concepts. Moreover, PAV seems to be committed to the claim that every competent speaker, just by virtue of her competence, knows these rules and thus possesses those concepts. I will discuss this claim soon, but first I will illustrate its consequences with an example drawn from (a somewhat dated version of) Binding Theory (see Chomsky [1981]), one of the central components of the Principles and Parameters tradition in generative linguistics. Take Principle A, for instance:

(Principle A) An anaphor must be bound in its local domain.

This principle explicitly contains concepts such as BINDING and LOCAL DOMAIN, and since BINDING, under this theory, essentially involves concepts such as C-COMMAND and INDEX, these concepts are thereby also encompassed within the principle.

Thus, if we adopt PAV we get the following picture. Suppose that a speaker $\mathrm{S}$ is competent in the production and understanding of anaphoric expressions in English. Moreover, as a manifestation of her competence, $\mathrm{S}$ also has a series of intuitive judgments about the linguistic status of expressions containing anaphors. For instance, she would find (1) acceptable but (2) unacceptable.

(1) John likes himself

(2) *John's mother likes himself 6

A linguist would naturally interpret S's judgments as evidence that (1) is grammatical in S's idiolect, but (2) is not. This difference can be captured in terms of Principle A of Binding Theory. The explanation of the ungrammaticality of (2) is that it violates Principle A, because 'himself is not bound in its local domain, as neither of the potential binders actually binds the reflexive. ${ }^{7}$

Now, the PAV theorist would explain S's judgments, and in general S's competence, by attributing to $S$ (tacit) knowledge of Principle A. Hence, she is committed to ascribing to $S$ the concepts that the principle contains, so that $\mathrm{S}$ must possess the concepts ANAPHOR, BINDING, and LOCAL DOMAIN. Moreover, since knowledge of Principle A involves knowledge of the definition of BINDING, PAV is also committed to attributing to $\mathrm{S}$ the concepts COINDEXED (A, B) and CCOMMANDS $\angle \mathrm{A}, \mathrm{B}>$, which entail a further set of notions pertaining to the geometry of syntactic trees, such as DOMINANCE, NODE, etc.

Some authors are open about this commitment; for instance, Higginbotham ([1998], pp.195-6, italics mine) says that:

${ }^{6}$ Asterisks are commonly used in linguistics to indicate that a sentence is ungrammatical or unacceptable.

7 'John's mother' c-commands 'himself, but cannot be coindexed with it, due to lack of gender agreement. Likewise, 'John' does not c-command 'himself, because there is at least one node that dominates the first but not the second, namely the one occupied by the determiner phrase (DP) 'John's mother'. 
The concept C-COMMAND is [...] deployed by speakers and hearers in determining the possibilities for pronominal cross-reference, in English and other languages, with differences from language to language that are the subject of active research. Pathologies apart, speakers and hearers not only have the concept, but also bave an adequate conception of it, even in the absence of any conscious view.

From this it can be gathered that every competent speaker possesses the concept CCOMMAND, with the qualification that she does so tacitly.

\section{The Argument from Concept Possession}

\subsection{Motivation}

Understanding the notions involved in contemporary linguistic theory requires a non-trivial degree of intellectual sophistication and capacity for abstract thought, yet some individuals who seem to lack the indispensable cognitive wherewithal are nonetheless competent speakers. ${ }^{8}$ Good examples of this are normal elementary school children, as well as adults in whom severe cognitive impairments coexist with relatively intact linguistic abilities. ${ }^{9}$ Considerations like these prompt doubts about the attribution of grammatical concepts, and such doubts are the starting point for an argument against PAV.

\subsection{The Argument}

Let us call the argument against PAV that is based on this intuition the Argument from Concept Possession. ${ }^{10}$ To get us started we need a premise that makes concept possession a necessary condition

\footnotetext{
${ }^{8}$ See, in this respect, the discussion in Wright ([1986], p. 218-22) and in Davies ([2001]).

${ }^{9}$ See Smith and Tsimpli ([1995]) for the remarkable case of Christopher, a linguistic savant. Another striking example is that of children with Williams Syndrome, whose scores on full scale IQ tests are typically in the range of 50-70, but who are nonetheless able to recognize and have accurate judgments about whether a sentence conforms to the locality requirement in Principle A (Zukowski [unpublished]), and whose performance on complex morphosyntactic phenomena such as reversible passives, reflexive anaphors, and regular past tense inflection is not impaired (Clahsen and Almazan [1998]).

${ }^{10}$ Devitt ([2006a], [2000b], [2000c]) attacks a position that is essentially the same as 'PAV', and which he labels the 'Representational Thesis' (RT). RT, along with what he calls the 'Voice of Competence' (VoC) view of linguistic intuitions, forms what Devitt understands as the Standard Chomskyan (and Chomsky's) interpretation of linguistics. Devitt argues that there is no evidence for the view that speakers represent the principles of grammar in their language faculty, or indeed for the thesis they stand in a propositional attitude relation to their grammars.

Collins ([2004], [2006], [2007], [2008]) is another critic of PAV. He points out that the expression 'knowledge of language' is a collocation peculiar to the English language, not the description of an epistemological condition that philosophers should strive to accommodate. Furthermore, the picture of the language faculty
} 
for holding propositional attitudes. Such a premise could be:

(Premise 1)

For a subject $\mathrm{S}$ to have a propositional attitude towards a proposition $\mathrm{P}, \mathrm{S}$ must possess the concepts that appear in $\mathrm{P}$.

Premise 1 presupposes that believing a proposition requires possessing its component concepts. This fits with the view that thoughts or propositions ${ }^{11}$ are structured entities, composed by concepts. ${ }^{12}$ Thus, I will treat concepts as thought components.

Before we proceed further I would like to make some comments about my formulation of the Argument from Concept Possession:

First, it is framed in terms of belief, though its conclusions can be extended to knowledge, provided knowledge entails belief. I chose to use 'belief' instead of 'knowledge' for no other reason than to avoid issues about factiveness and justification. ${ }^{13}$ Second, in this paper, 'linguistic proposition' designates those propositions containing grammatical concepts such as BINDING, CCOMMAND and the like. 'Grammatical' or 'syntactic' concepts (I am using these terms interchangeably, for the purposes of this paper) are the concepts—of linguistic objects, properties and relations - that figure essentially in the substantive generalizations of theories in the Principles and Parameters tradition. ${ }^{14}$ Third, I take concepts, explicit or otherwise, to be a kind of mental content. Section 4 aims to identify the features that set concepts apart from other species of content.

offered by the Principles and Parameters approach militates against epistemic construals of linguistic competence.

Unlike both Collins and Devitt I will make no assertions about whether Chomsky ever held PAV, if only because I wish to stay away from Chomsky exegesis (I take it that the elucidation of his views, especially earlier ones, is still an contentious issue. See Devitt ([2006]) and Collins ([2004]), for conflicting interpretations of certain key passages).

Also, I will make no claims as to whether PAV is the view that most working linguists assume, since I suspect that many of them have few or no settled commitments in this respect. Nevertheless, I do hold that PAV has been sufficiently attested in the literature (see note 4), so as to merit discussion, independently of what Chomsky's views actually are.

Finally, whereas Devitt's wider project is an attempt to undermine the (mainstream) view that linguistics is a branch of cognitive psychology, my criticism of PAV will be framed within the context of that view.

${ }^{11} \mathrm{I}$ am using 'proposition' and 'thought' indistinctly and in an ontologically neutral way, just to make reference to whatever it is that constitutes the contents of propositional attitudes.

${ }^{12}$ There are several ways of filling out the details of this schematic picture, some Platonic, some psychologistic, etc., but to anchor the rest of the discussion, let us assume that concepts are (or are represented by/correlate with) mental items which combine in structured ways to form thoughts (or representations thereof).

${ }^{13}$ There are defenses of the notion of knowledge of language - though not necessarily of grammar-that do not involve belief (see Smith [2006a], [2000b]; Matthews [2006]). However, since, those views do not require the relevant states to be propositional attitudes, I will not discuss them here.

${ }^{14}$ This is meant to exclude, on one side, mere notational conventions and matters of representational technology, and on the other, extragrammatical or clearly non-syntactic concepts, such as those in the domain of pragmatics. Again, I'm taking syntax as the central case, so my conclusions are meant to apply to syntactic concepts first and foremost. The extent to which they can be applied to semantics and phonology is an interesting topic that will have to be taken up elsewhere. 
So here's the argument:

(Argument from Concept Possession)

1. If $S$ believes linguistic proposition $P$ then $S$ possesses linguistic concept $C$ (which appears essentially in $\mathrm{P}$ ).

2. $\mathrm{S}$ does not possess $\mathrm{C}$.

3. $\mathrm{S}$ does not believe $\mathrm{P}$ (from 1 and 2 ).

4. If PAV is true then $\mathrm{S}$ believes $\mathrm{P}$.

5. So, PAV is false (from 3 and 4).

The objective of this paper is to defend the argument above. In section 3 I briefly discuss Premise 1, as well as some constraints on concept possession. The bulk of this essay, though, is devoted to the justification of Premise 2. More specifically, in section 4 I propose a criterion of concept attribution aimed at settling controversial claims about implicit concept possession. I arrive at this criterion by surveying the kind of evidence typically relied on to attribute concepts, and then focusing on a collection of cognitive dispositions that bear crucially on concept ascription. These dispositions turn out to share the property of being manifestations of 'domain crossing', where a content crosses domains iff it can be applied to, or is able to exert direct influence over, a plurality of cognitive domains. This forms the basis for what I call the Domain Crossing Criterion of concept possession, which, in a nutshell, says that $\mathrm{S}$ possesses concept $\mathrm{C}$ only if $\mathrm{C}$ crosses domains in S's cognitive economy. I argue that grammatical concepts do not satisfy this condition in the case of naïve speakers. Hence, naïve speakers do not possess such concepts.

\section{Premise 1: Concepts, Thoughts and Persons}

The view according to which concepts are components of thoughts is the orthodoxy at least within the Fregean tradition in the philosophy of thought, and is also an essential part of the Language of Thought hypothesis. ${ }^{15}$ This view has been characterized and defended elsewhere, ${ }^{16}$ so I will devote the rest of this section to what I consider a fundamental constraint on concept attribution.

The constraint I am proposing is that concepts must be attributed at the personal level. One

15 According to Peacocke, for example, concepts are 'constituents of complete contents which are evaluable as true or as false' ([1996], p. 407), and for Fodor ([1998], p. 25) concepts are 'constituents of thoughts, and, in indefinitely many cases, of one another'.

16 See Evans ([1981]); Fodor and Pylyshyn, ([1988]); Crane, ([1992]), among others. 
clue as to why this should be so is that concepts find a natural place in the context of a certain kind of content-involving explanation, namely, rationalizing explanations. Rationalizing explanations of action seek to render an agent's action $\mathrm{x}$ intelligible in the light of her reasons to do $\mathrm{x}$. The background assumption is that the agent whose actions are to be explained is rational, and that her action will become understandable once we set it against the background of the contents of her beliefs and desires, as well as her inferential capacities. ${ }^{17}$ Thus, rationalizing explanations function at the personal level, ${ }^{18}$ as they involve the personal level ascription of propositional attitudes and their contents, that is, thoughts. In its turn, the attribution of a thought requires the attribution of its components, which we take to be concepts.

Concepts, then, must be understood vis-à-vis their role in attributions of personal states, such as believing, desiring or intending. Crucially, just as we require attributions of propositional attitudes towards thoughts to be personal, we also require that the concepts constituting those thoughts be personal. The notion of concept is, then, part of a suite of notions that co-occur in personal-level rationalizing explanations, and which has the notions of belief, desire, intention and the like among its members.

In what remains of this essay I will assume that concept attributions, in the context of rationalizing explanations, are pitched at the personal level. I will not provide an argument for it here because I wish to devote my efforts in this paper to the discussion of the second premise, and so a defense of that assumption will have to be taken up elsewhere.

So, if you wish, you may understand the conclusions in this paper as being conditional on the assumption of the personal-level character of concept attribution: if one assumed that concept attribution is personal then PAV is false.

However, I do think that it is a reasonable hypothesis to assume, given certain plausible suppositions about the role of concepts and propositional attitude attributions in the context of rationalizing explanation. ${ }^{19}$ In consequence, once we accept the prima facie plausibility of this assumption, we place the burden of refutation on the skeptic's shoulders.

In view of this, PAV's competence-based explanation of language capacities turns out to be an instance of rationalizing explanation, ${ }^{20}$ and so the attribution of the pertinent concepts must

\footnotetext{
${ }^{17}$ See Lepore ([1996]) for a discussion of rationalizing explanations of semantic competence.

18 The present usage of 'personal' and 'sub-personal' states or levels originates with Dennett ([1969]).

19 Two of these assumptions have already been mentioned or hinted at, namely: (a) that rationalizing explanations involve the ascription, at the personal level, of propositional attitudes and thoughts (the contents of the attitudes) to an agent, and (b) that the attribution of a thought involves in its turn the attribution of its immediate components.

20 Thus, the sketch for an explanation of a speaker's choice of pronoun in a particular occasion could go like this: (a) $\mathrm{S}$ wants to communicate in English a thought of the form Loves $<\mathrm{x}, \mathrm{x}\rangle$, where $\mathrm{x}$ is John, and she wants to express it with a sentence in which 'John' is the subject and where a pronoun is in the direct object position. Now, since: (b) S believes that any pronoun that indicates the object of John's love will be (i) c-commanded by
} 
satisfy the personal-level constraint. ${ }^{21}$

Another distinction worth mentioning, which is intimately related to the personal/subpersonal dimension, is that between doxastic and subdoxastic cognitive states. Doxastic states, such as belief, are inferentially integrated, i.e. they can combine with further contentful states to yield consequences. In Stich's words ([1978], p. 507), beliefs are 'inferentially promiscuous'.22 Subdoxastic states, on the other hand, are 'largely inferentially isolated from the large body of inferentially integrated beliefs to which a subject has access'. What best defines subdoxastic states, then, is their comparatively poor potential for inferences. Beliefs, which are personal states, are doxastic as well as conceptual. Concepts, then, are typically associated with doxastic states. Typical examples of non-personal states, such as those occurring at the early stages of perception, are also standard examples of subdoxastic states. $^{23}$

\section{Premise 2: Naïve Speakers Lack the Required Concepts}

\subsection{The search for a criterion of tacit concept attribution}

A defense of premise 2 involves finding reasons for denying possession of grammatical concepts to naïve speakers.

Both sides in the debate agree that the core evidence for the postulation of C-COMMAND in

'John' (because of its position in the structure), and (ii) co-indexed with 'John' (given that she wants to convey that John's love is self-directed); and since: (c) S believes condition A of Binding Theory, then (d) she forms an intention to utter the sentence: 'John loves himself.

${ }^{21}$ There is textual evidence for the claim that PAV's competence-based explanation of language capacities turns out to be an instance of rationalizing explanation, or at least that it involves propositional attitudes and inference. For instance,

Graves et al ([1974], p. 325), claim that speaker's judgments about the grammatical properties of sentences are the result of 'a tacit deduction from tacitly known principles'.

According to Dwyer and Pietroski ([1996], p.340) their view (if true) offers a significant empirical constraint on doxastic theories. Moreover, they assume that beliefs are, among other things, 'mental states', and that they 'figure in folk psychological explanations of behavior and inference' ([1996], p.340, emphasis mine). Since this is a constraint on beliefs in general, the one must suppose that it is a constraint on 'linguistic beliefs' as well, but folk-psychological explanations are commonly thought to be personal level and rationalizing. As for the modus operandi of linguistic explanation, they say that, on their view, 'the linguist explains a hearer's grammaticality judgments as the result of an inference based on genuinely intentional states' ([1996], p. 342).

22 'Provided with a suitable set of supplementary beliefs, almost any belief can play a role in the inference to any other $[\ldots]$ it is in this sense that a person's beliefs are inferentially integrated' (Stich, [1978], p. 506).

${ }^{23}$ Nevertheless, the distinctions are not necessarily coextensional. Perceptual experience is mainly personal (pain and other sensations are one of Dennett's ([1969]) main examples of personal states), but it is sometimes construed as subdoxastic and nonconceptual (see Bermúdez and Cahen ([2010]); Crane ([1992])). Presumably, there are no doxastic subpersonal states, and so doxastic states would be a proper subset of personal states (though see Schiffer ([1998]), where he discusses 'subpersonal propositional attitudes').

In this paper I assume that personal and doxastic states can come in both conscious and non-conscious varieties, whereas subdoxastic and subpersonal states are invariably unconscious. 
linguistic theory is constituted by the speaker's competence in her native language, ${ }^{24}$ they part company, however, on the issue of whether such evidence is sufficient for ascribing C-COMMAND to the speaker.

To adjudicate the issue, it seems, we should agree on a suitable criterion of concept attribution. This criterion should provide at least a necessary condition for concept possession, thus allowing us to discriminate between cases of tacit conceptual content and nonconceptual content.

Besides this initial characterization, the criterion must meet further conditions. The first one is that is must be neither so restrictive that it leaves out cases of genuine concept possession, nor so lax that includes cases that do not involve concept possession. Second, for the criterion to be informative it must be empirically discriminative, that is, it should afford us a specification of the sorts of evidence that support or undermine the hypothesis of tacit concept possession. An example of a criterion that would be theoretically plausible but not empirically discriminative would be: ' $A$ possesses concept $\mathrm{C}$ only if $\mathrm{A}$ can entertain thoughts (have attitudes with contents) that include $\mathrm{C}$ as a constituent'. This criterion would only be useful if, given a body of evidence, thought attribution were considerably easier or less controversial or more basic than the attribution of concepts. But this does not seem to be the case, and in consequence such a criterion does not make our task any less complicated.

A more helpful criterion would be empirically discriminative: it would give us guidance as to what kinds of (say) cognitive dispositions are symptoms of implicit concept possession (i.e. what sorts of inferences, learning outcomes and different cognitive activities, etc.) Thus, the chosen criterion must be pitched in terms abstract enough to cover a broad range of cases of conceptual possession, yet concrete enough to have empirically discernible implications.

Also — and ideally — this criterion would follow straightforwardly from a plausible theory of implicit concept possession. However, it is unlikely that this will happen, for at least two reasons: first, although the philosophical literature on concepts is abundant - in fact too vast to receive a fair treatment here-work on implicit concepts is relatively scarce. ${ }^{25}$ Thus, we must draw resources from related areas, such as theories of concepts (simpliciter) and theories of implicit (doxastic, personal) content. I won't explore theories of concepts in depth, because the main philosophical proposals about concepts stand at a considerable remove from the empirical details of concept attribution,

${ }^{24}$ I will use C-COMMAND as a representative example of the kinds of concepts I am discussing, but the same considerations can be applied to other theoretical concepts in Generative Grammar, such as BOUNDING NODE, CASE, SPECIFIER, and so on.

${ }^{25}$ Though see Peacocke ([1998]) and the rest of the articles contained in that issue, which was entirely devoted to Peacocke's work on implicit conceptions.

On the general topic of concepts, see Peacocke ([1992]) and Fodor ([1998]) for statements of views that have steered much of the debate. 
and dispute can arise as to how to apply them to concrete cases. Thus, they are unlikely to yield the empirically discriminative criterion we are interested in. ${ }^{26}$

Another theoretical source is the rich literature devoted to related doxastic notions, such as tacit 'knowledge' and 'belief. ${ }^{27}$ In particular, theories of tacit propositional attitudes are worth paying attention to, given that concept and attitude attributions intertwine with each other. Among these theories, Crimmins' ([1992]) 'virtual belief' account of tacit belief is both pertinent and plausible, and I will use it as a model for my discussion.

My reasons for endorsing Crimmins' approach are twofold: the first has to do with the theory's merits per se. It has at least the same explanatory power as more traditional alternatives, ${ }^{28}$ while being immune to most of the challenges on which theories of tacit attitudes have foundered (see Lycan, 1986; Crimmins, 1992). The second reason for preferring Crimmins' view is that it fits my purposes better than other theories. This is because that it provides a general view about the ascription of tacit doxastic states, which can be easily and naturally extended to concepts, and so it suggests a strategy for seeking a criterion. I will take it Crimmins approach, then, as a starting point.

\footnotetext{
${ }^{26}$ Evans' ([1981], [1982]) Generality Constraint (GC) is a condition on concept possession, and as such it is potentially relevant to our discussion. According to Evans, having a concept involves being able to single it out and grasp the range of its combinatorial possibilities. A thinker who possesses the concept FAT will not only be able to contemplate the thought that Albert is fat, but also that Bill is fat, that Godzilla is fat, and so on for other individuals. So, the question is: are C-COMMAND and the like fully recombinable in a naïve competent speaker's mind? The answer to this question will depend on the range of thoughts involving C-COMMAND that such a speaker can form. The answer will depend on the range of C-COMMAND- involving thoughts that such a speaker can form. This, in its turn, will require us to use the evidence to determine, for a specific series of thoughts, whether the speaker can have them. However, there is no reason to think that whether a speaker can entertain a given thought of the form $x$ c-commands $y$ will be any less controversial (or more basic) than the issue of whether that speaker possesses the concept C-COMMAND. Thus, trying to answer the kind of questions the GC makes available doesn't get us any closer to overcoming the impasse between attributers and nonattributers. As I explain below in the text, we need an "empirically discriminative" criterion, and the GC by itself does not seem to be able to provide this.

${ }^{27}$ A prima facie relevant line of work goes under the heading 'tacit linguistic knowledge', and constitutes an elaborate response to Wittgensteinian and Quinean skepticism about knowledge of semantic rules. Among its contributors are Evans ([1981]), Davies ([1987], [1989]), Wright ([1986]), and Peacocke ([1986]), who have advanced views on the nature of tacit knowledge of language, though almost always dealing with semantics, rather than syntax. However, these authors tend to characterize 'tacit knowledge' as 'subdoxastic', that is, as belonging to a class of states that, although content-bearing, do not qualify as fully-fledged propositional attitudes (Davies [1987]; [1989]; Evans ([1981]), Evans ([1982]); Stich ([1978]). See also the previous discussion of subdoxasticity in the text.). For these authors linguistic content occurs at a subdoxastic level, and so is not the basis for genuine propositional attitudes and their conceptual constituents. So, states thus characterized fail to meet the personal level/doxastic constraint on concepts set above. These theories are then (for our purposes) clear nonstarters. Other nonstarters (albeit for diverse reasons that for lack of space I will not discuss here) are earlier criteria of tacit knowledge put forward by Fodor ([1968]), Nagel ([1969]) and Graves et al ([1973]).

${ }^{28}$ Such as dispositional accounts (De Sousa [1971]; Maloney [1990]), or what Lycan ([1986]) calls 'simpleconsequence' views, such as Field, ([1978]) and Dennett ([1978]).
} 


\subsection{Tacit Attitudes, Tacit Concepts and Cognitive Dispositions}

According to Crimmins, tacit belief attribution is dependent, at least evidentially, on explicit attribution: instances of tacit ascription are legitimate only to the extent that they resemble - to a certain degree and in certain relevant respects - corresponding cases of ascription of explicit beliefs. What drives the ascription of tacit attitudes, then, is similarity with a case of explicit possession. This is the condition on tacit attribution that Crimmins proposes:

A at-least-tacitly believes $\mathrm{p}$ just in case it is as if A has an explicit belief in $\mathrm{p}$.

So, according to this view we can only attribute to (e.g.) a small child the belief that red objects are square if it is as if the child has such a belief, even if he is incapable of reflecting or reporting its contents.

At the base of tacit attitude attribution, then, there is an implicit comparison between A's cognitive situation and another situation in which someone-perhaps A herself in a hypothetical scenario- has the corresponding explicit attitude. In the example above, the reference situation (of explicit possession) may be that of a cognitively normal adult who has the explicit belief that red objects are square.

For this criterion to be informative it is necessary to specify the respects in which tacit states must resemble explicit states. For Crimmins ([1992] p. 249) this resemblance — the 'being as if is cashed out in terms of cognitive dispositions, that is, dispositions towards 'forming beliefs and intentions and to attempt actions'. Thus we arrive at the final formulation of Crimmins' criterion:

A at-least-tacitly believes $\mathrm{p}$ just in case A's cognitive dispositions are relevantly as if $\mathrm{A}$ has an explicit belief in $\mathrm{p}$.

The dispositions in question need not be construed at a very fine-grained level, and there is no need to look for detailed similarities at the level of cognitive processes. Instead, we focus on the 'broad upshots' of those processes, such as decisions, conclusions reached and emotions had. Second, similarities in higher-order attitudes (such as higher-order beliefs, desires, as well as mental acts like reflecting, introspecting and the like) do not play any part in the comparison, because if those were to obtain in A's actual situation, then the belief in question would not be tacit, but explicit.

The application of this view to the case at hand is quite natural, and by replacing 'belief' with 
'concept' we obtain a first stab at a criterion for tacit concept attribution:

A at-least-tacitly possesses concept C just in case A's cognitive dispositions are relevantly as if A had concept $C$ explicitly.

A formulation of this kind would probably be acceptable as it stands if we were merely interested in giving a general account of the nature of tacit possession, which is was Crimmins was trying to do in the case of belief — and so it was appropriate for him to leave questions of empirical applicability unanswered. However, since we are aiming at an empirically discriminative criterion, we must be more specific, since cognitive dispositions can resemble each other in innumerable ways, and not all of them are relevant for our purposes.

\subsection{Domain Crossing And Its Manifestations}

So, in which ways must cognitive dispositions resemble those of the explicit case?

As an answer to this question I propose what I call the 'Domain Crossing Hypothesis', namely, that the cognitive dispositions in the implicit case must manifest 'domain-crossing', just as those in the explicit case do. Domain crossing is a property of concepts (qua contents), which I characterize thus:

(Domain Crossing) A given content crosses domains iff it can be directly applied to or is able to exert direct influence over a plurality of cognitive domains or spheres (a discussion of this will come later).

Domains, in this case, can be subject matters, theories, conceptual structures, or even tasks or situations associated with particular conceptual demands. So, a concept crosses domains when it is deployed in context $y$, though it has been acquired, or is standardly used in a different domain $\mathrm{x}$.

The following is a hypothetical but illustrative example of domain crossing. Consider the concept PARABOLA, as possessed by Mary, an engineer and overall versatile person. She can apply the concept in solving abstract mathematical problems, as well as problems about (say) the trajectory of projectiles. Deployment of the concept can also help her understand the principles behind the design of the wire strand cables of the Golden Gate Bridge, and may also guide her in designing antennas of radio telescopes. She also recruits the concept to teach her son the notion of 
a conic section, or to play a competitive game in which one must run in what is intuitively a parabolic trajectory. She also uses it in thinking metaphorically about the life course of a historical figure whose fortunes progressively rise and then fall.

In this case, PARABOLA seems to be directly pressed into service by many different cognitive processes, for the fulfillment of sundry cognitive tasks. This includes general problem solving, analogy making, metaphor production and understanding, and many others. It is also applied in thinking about a wide variety of objects, from mathematical objects to artifacts human lives. It also occurs in the fulfillment of tasks of quite diverse nature, such as mathematical reasoning, spatial reasoning and motor control, for instance. Thus, in Mary's case we are quite confident that PARABOLA crosses domains.

For the notion of domain crossing to fulfill its role in an empirically discriminative criterion we must determine which kinds of cognitive dispositions constitute evidence of domain crossing. As illustrated by the example above, flexible deployment in discrimination and reasoning in heterogeneous tasks is a clear indication of domain crossing. For instance, a domain-crossing content can figure in premises used in the agent's reasoning, such as 'If $\mathrm{x}$ is a parabola then Q', where $\mathrm{x}$ and $\mathrm{Q}$ can stand (respectively) for a variety of objects and propositions that participate in different antecedents of action and belief, in different cognitive contexts and tasks.

Another kind of cognitive disposition that evidences domain crossing is what we can call "nonliteral applications". These go beyond the standard applications we have mentioned so far and come into play in devices such as metaphor and metonymy, in jokes, and in games or other activities that involve pretense. In these cases we find the possibility of cross-categorial applications, that is, of deployment of the concept in ways that depart from its standard categorial profile (e.g. treating numbers as if they were animates; Mary's thought that Napoleon's existence was a parabola, etc.), and where this does not come about through mistaken beliefs about the objects in question.

Last, there is a related group of dispositions and outcomes that allow a content to be manifested, albeit in an indirect way, which I call 'cognitive transfers'. An example is the facilitation (or hindrance) of cognitive outcomes_-such as learning or reasoning - in one domain by contents in another domain. This is most obviously exemplified by analogical reasoning, and is conspicuously present in cases of scientific discovery and (successful) school learning, where knowledge in one area can be a natural springboard for acquisition, learning or reasoning in another.

Thus, we have identified three kinds of dispositions that are prima facie indicators of domain crossing: use in discrimination and reasoning, non-literal applications and cognitive transfers (of course, this list is by no means exhaustive). 
The notion of domain crossing — and in consequence the criterion — contains a crucial notion that needs clarification: the distinction between direct and indirect application (or influence). This contrast is needed to rule out cases that at a first glance look like domain crossing but which are not, as illustrated in the following example. Suppose that $\mathrm{Al}$ sees Beth for the first time. In the course of processing Beth's facial features, Al's perceptual system (which we take to be subpersonal) tacitly computes and registers, say, a measure of the symmetry of Beth's facial features. Let us call this measure, which is representational in character, $\mathrm{s}$. The content of s (tacitly) contributes to Al's intuitive appraisal of Beth's overall attractiveness, and thus to Al's belief that Beth is physically attractive. Beth's perceived attractiveness is in its turn one the factors that enter Al's (personal-level) deliberation as to whether he should approach Beth for conversation, along with e.g., Al's fear of rejection, self-image, likelihood of success, etc.

So, s has cognitive influence over Al's decision to approach Beth, as it contributes to an overall impression of attractiveness at a personal level. However, the influence of $\mathrm{s}$ on his decision is indirect, as it is not directly applied or adverted to in the deliberation process that leads to Al's choice. This is because it is unlikely that s itself-as opposed to the predicate ' $x$ is attractive' - is a component of one of the premises in Al's deliberation, or one of the relevant personal-level considerations behind his choice. Thus, the fact that s has some degree of cognitive influence beyond its original domain (face perception) does not support the view that s crosses domains, and a fortiori does not support the view that $\mathrm{s}$ is conceptual.

Beth's perceived attractiveness, on the other hand (or the corresponding concept) is a better candidate for playing a direct role in Al's personal-level considerations and thus for being directly applied in the processes leading to his choice. Analogously, as Mary's example was described, it is plausible that in her case PARABOLA did make a direct contribution to her thought processes qua agent.

\subsection{The Domain Crossing Criterion}

Recapitulating, we had proposed that A at-least-tacitly possesses concept $\mathrm{C}$ just in case A's cognitive dispositions are relevantly as if $\mathrm{A}$ had concept $\mathrm{C}$ explicitly. And since we just hypothesized that A's cognitive dispositions are relevantly as if $\mathrm{A}$ had concept $\mathrm{C}$ explicitly just in case A's cognitive dispositions with respect to $\mathrm{C}$ — "C-involving dispositions", for short — manifest domain crossing, we arrive at the following proposal:

Domain Crossing Criterion. 
A at-least-tacitly possesses concept C just in case A's C-involving dispositions manifest domain crossing.

This criterion satisfies the main requirements set above, namely, its formulation abstract enough to cover a broad range of cases of conceptual possession, yet concrete enough to have empirically discernible implications.

Now the question is whether the criterion works. To argue for its plausibility, it must be shown that instances of tacit concept possession in general exhibit domain crossing (minus those aspects that depend on explicitness, of course). Crucially, we must also show that the criterion is not too liberal, by showing that cases of content ascription that are not conceptual do not show domain crossing. In the following section, I identify cases of attribution of tacit contents that are reasonably thought of as conceptual in nature, and will argue that, although lacking explicitness, they nonetheless feature domain crossing.

\subsection{Domain Crossing and Tacit Concepts}

Peacocke ([1998], pp. 48-51) mentions an interesting example of tacit concept possession in his discussion of Newton and Leibniz's 'grappling with the notion of the limit of a series', a fundamental notion for the explication of the differential calculus. These authors lacked the resources to provide an explicit characterization of the concept LIMIT OF A SERIES; however, it would be unfair to say that they lacked the concept, because, among other things, they were able to differentiate particular functions, and they had no difficulty in saying what the limit of a particular series of ratios was, and the best explanation for this is that they were implicitly deploying the notion. So we could say that Newton and Leibniz possessed LIMIT OF A SERIES implicitly (Peacocke speaks instead of 'implicit conceptions', which are slightly different from 'implicit concepts', though the distinction does not concern us here).

Moreover, the application of the concept was not in their case stereotypically or mechanically tied to just one kind of problem, but also influenced other areas of research, such as metaphysics (Leibniz), and physics (Newton).

There are other examples of what we could plausibly think of as tacit concepts. Some of them (unlike LIMIT) are acquired independently of formal education or special talent, as is the case with basic notions such as Animate, Agent, CAuse, ObJeCt and Number, among others. These inform the functioning and development of vast areas of cognition and perception, are 
attributable to both preschool children and adults, ${ }^{29}$ and are typically assigned conceptual status by researchers. ${ }^{30}$ In the discussion that follows I will focus on a particular member of this class: ANIMATE.

Preschool children typically lack an explicit conception of ANIMATE, as they are unable to report on its contents, or to explicate them, or to perform any task that depends on these abilities. However, just as explicit possessors, preschoolers are adept at discriminating animates from inanimates, and they can use the notion for reasoning in a broad variety of areas. For instance, on the basis of the animate-inanimate distinction they are able to judge, from an array of objects, which of them can possess biological properties and undergo biological processes, such as growth, healing, reproduction, inheritance, illness, contagion and death (Gutheil, Vera, \& Keil, [1998]).

Furthermore, they are able to combine the implicit content of the concept with various explicit contents so as to yield novel inferences. Thus, Opfer \& Siegler, ([2004]) taught a group of preschoolers, who were unaware of plant motion, that plants can move in goal-directed ways. They immediately inferred that plants— like animals—are living things, too, deriving from this an array of animacy-related consequences.

The concept can also be put to use in more abstract tasks, such as judgments of categorial appropriateness, as shown by a study reported by Keil ([1979]), where 4-year-olds were able to recognize the inappropriateness of applying animate-appropriate predicates to artifacts (e.g., 'The chair is asleep' was judged as 'silly').

Preschool children are also capable of non-literal applications of ANIMATE: they can deploy the notion in games and in metaphor, both in production and in comprehension. Pretense-play provides a good example: a child may assign animate-like properties to a doll, which she knows to be inanimate. Five year olds also show competence at understanding metaphors that depend on animacy (Gottfried, [1997]).

Last, it can be argued that animate can perform a role in cognition that is analogous to that of cognitive transfer, as the notion is at the center of a vast cluster of conceptual distinctions that enable several aspects of cognitive development. Among these are the acquisition of word meaning and syntax, the understanding of metaphor, the causal interpretations of action, the attribution of mental states and the attribution of biological processes, among others (see Gelman and Opfer, [2002]; Rakison and Poulin-Dubois [2001]; Carey [1985], chapter 1). These can be

\footnotetext{
${ }^{29}$ There is evidence that the distinction between animate and inanimate entities (first applied to people and later to animals) is well in place very early in infancy, and it has also been proposed that it is already in its stable, robust form by the end of the preschool years, if not earlier (see Gelman and Opfer [2002]).

${ }^{30}$ See Poulin-Dubois, Lepage and Ferland ([1996]); Shutts, Markson and Spelke ([2009]), for example. ANIMACY gets recruited in infants' conceptual understanding of the world (as measured by, for example, emotional responses, imitation, generalization, or causal attributions) (Gelman and Opfer, [2002], pp. 152-55).
} 
understood as very deep cases of cognitive transfer. This role manifests itself in the course of development, and so is unlikely to have a close counterpart in the situation of the cognitively mature explicit possessor that we described earlier.

We can see then, that the relevant cognitive dispositions exhibited by tacit possessors of the concept ANIMATE-preschool children in this case - show clear signs of domain crossing, in the form of discriminative abilities, usability in problem solving and reasoning, especially in areas different from the canonical or learning situation, as well as non-literal applications. As a more tentative observation, we also included cognitive effects.

To sharpen the contrast we must find out whether domain-crossing dispositions are missing in cases where concept attribution would clearly be illegitimate. For this purpose we can consider those concepts that appear in computational theories operating at the sub-personal level. Examples can be found in computational theories of early vision, in the tradition of Marr ([1982]). Let us consider, for example, the algorithm for detecting edges, via zero-crossings, which uses Fourier transforms (Marr [1982], pp. 54-7).

I take it that it would be wildly implausible to say that a perceiver, just in virtue of her ability to detect edges in the environment, possesses the concepts ZERO-CROSSING or FOURIER TRANSFORM, not only because people with no training in mathematics are as competent at visual tasks as someone who has explicit mastery of those notions, but also because, since the visual systems of other mammals are similar to the humans', we expect monkeys, dogs, and cats-who are also proficient at detecting edges - to implement a similar computational procedure. So, this is definitely not a case of tacit concept possession.

Correspondingly, we have reason to think that domain crossing-indicating dispositions (or at least most of them) do not obtain for ZERO-CROSSING or FOURIER TRANSFORM in the case of mathematically naïve subjects.

Certainly, a competent perceiver under appropriate conditions would give plenty of evidence of being able to (implicitly) discriminate edges from non-edges. Nevertheless, he would not be able to apply the concepts in question to a wide range of problems, outside of the mechanical, encapsulated process of detecting edges. Likewise, these concepts seem unavailable for deployment in metaphor, pretense, humor or other non-literal applications, for example. Cognitive transfers are also absent, given that being able to detect edges does not facilitate learning or problem solving in (e.g.) any areas of mathematics or physics, which would be obvious areas of application.

Other clear examples can be found in the study of motor skills. For instance, it has been 
found that successful ball fielders run 'at a speed that kept the acceleration of the tangent of the angle of elevation of gaze to the ball at 0' (McLeod and Dienes, [1996], p. 531); see also the discussion in Devitt ([2006a], p. 50). This is not, however, grounds for attributing TANGENT OF AN ANGLE to the players: its applications are quite circumscribed to the area of ball-catching, and being a competent fielder typically does not influence learning and performance in trigonometry or in any other applications that depart significantly from fielding.

The above considerations clearly suggest that domain crossing is found in cases of concept attribution - whether explicit or implicit - whereas it is absent in cases of nonconceptual content postulation. Thus, they provide support for the domain-crossing criterion.

Having established the criterion's worth, we must put it to work for the purpose it was intended. This will be done in the next section.

\subsection{Domain crossing and Grammatical Concepts}

We finally get to the payoff: do naïve speakers possess C-COMMAND? In the light o the proposed criterion, the question becomes: does a grammatical notion, such as C-COMMAND, meet the Domain Crossing criterion with respect to naïve speakers? It seems unlikely, since it shows few if any-of the hallmarks of domain crossing. Sure enough, if we take a set of sentences whose grammaticality depends in some way on a rule involving C-COMMAND, a competent speaker would typically be able to classify them in terms of acceptability. However, we do not expect the speaker to use the concept in solving problems in non-linguistic domains, and she will not instantiate any cognitive transfers involving C-COMMAND (such as learning or reasoning enhancement, or analogical reasoning. The case of Bloggs, discussed below, is relevant to this issue). The use of the concept in general reasoning appears rather limited, and seems unavailable for non-literal applications, as well, as its involvement seems circumscribed to the linguistic domain.

In consequence, C-COMMAND fails the Domain Crossing Criterion in naïve speakers. Thus: (a) the naïve speaker's cognitive dispositions towards C-COMMAND are different enough from those of the explicit possessor to discourage ascription of the concept, and (b) instead, the cognitive profile of C-COMMAND seems to fit non-conceptual explanations - such as those in the field of early vision — better.

\subsection{Summing up}


In this section I started by articulating and defending a proposal for the ascription of tacit concepts, based on existing theories of tacit attitude attribution (i.e. Crimmins', [1992]). The resulting criterion identified domain crossing as a condition for conceptual status. Next, I proposed certain kinds of cognitive processes and dispositions (discrimination and reasoning, nonliteral applications, cognitive transfers, etc.) as crucial manifestations of domain crossing. Upon examination, these signs of crossing were found missing in the c-command-involving dispositions of speakers, strongly suggesting that they do not possess the concept, and thus supporting premise 2 of the Argument from Concept Possession. Since we have taken C-COMMAND as representative of grammatical concepts in general this claim can be extended to them.

Premise 2, when combined with premise 1 -namely that if $\mathrm{S}$ believes linguistic proposition $\mathrm{P}$ then $\mathrm{S}$ possesses linguistic concept $\mathrm{C}$ (which appears essentially in $\mathrm{P}$ ) - entails that $\mathrm{S}$ does not believe P (premise 3). Thus, PAV is false.

\subsection{Objections}

\subsection{Grammatical concepts cross domains}

One line of argument against PAV is that the putative beliefs or knowledge states carrying grammatical information are inferentially isolated, and so cannot be propositional attitudes. See Stich ([1978]). See also Dwyer and Pietroski ([1996]), Higginbotham ([1987]) and Knowles ([1996]) for discussion and criticism of this kind of argument.

The Argument from Concept Possession is somewhat different, as it is couched in terms of concepts and concept possession, rather than belief. However, the notions of inferential integration and domain crossing are closely` related. So, supposing that $\mathrm{C}$ is a class of concepts, and that a $\mathrm{D}$ is a class of cognitive states whose contents essentially feature concepts of the kind C, then showing that D's are inferentially integrated (and thus doxastic) goes a long way towards establishing that C's are domain-crossing.

Dwyer and Pietroski ([1996]) argue that grammatical states (what they call L-beliefs) are inferentially integrated; thus their objection, if successful, would be a serious challenge to Premise 2 of the Argument from Concept Possession.

Their argument starts with the following scenario (see Dwyer and Pietroski [1996], 357-58): an individual named Bloggs (a naïve English speaker) is watching an experiment in which a subject is presented with two boxes. Bloggs eventually arrives at the following generalization: whenever the 
experimenter utters a grammatical sentence, ${ }^{31}$ the left box contains ten dollars and the right box is empty. Otherwise, when the experimenter utters an ungrammatical sentence, the left box is empty and the right box contains the money. Now suppose that the experimenter utters the sentence:

(3) *John and Bill think that Mary wants pictures of each other.

Then he asks Bloggs to pick a box. Since Bloggs is competent in English he rules (3) ungrammatical, thus arriving at the belief that the money is in the right box. According to Dwyer and Pietroski, the explanation for Bloggs' choice involves his belief that (3) is ungrammatical, which depends inferentially on his putative L-belief that anaphors must be bound in their local domain. Thus, Bloggs' L-beliefs can influence, and be integrated with, beliefs and desires involved in decision making in a non-linguistic domain (a choice between two boxes, in this case).

We may reconstruct Bloggs' reasoning thus:

Argument 1

(i) Sentence (3) is ungrammatical.

(ii) If a sentence is ungrammatical, then the right box contains $10 \$$.

(iii) Therefore, the right box contains $10 \$$.

Presumably, (i) - (iii) all describe the contents of Bloggs' explicit beliefs. Premise (i) is a straightforward linguistic judgment. Premise (ii) is crucial, because it links L-beliefs with nonlinguistic content. The content of (iii), together with some additional practical reasoning taking into account Bloggs' desires, eventuates in his choice of the right box.

Now, for the Bloggs scenario to do its work, L-beliefs and their components (i.e. grammatical concepts) must bear on this chain of reasoning as part of the grounds for (i). Thus, an argument such as the following should provide a (rational) basis for Bloggs' acceptance of (i):

Argument 2

(iv) In (3) 'each other' is an anaphor.

(v) In (3) 'each other' is locally free. ${ }^{32}$

\footnotetext{
31 From Bloggs' point of view we should probably formulate the generalization in terms of acceptability, or of a sentence being 'ok'. This is because grammaticality is a theory-internal notion (i.e. what status a grammar G assigns to a sentence S), which we be should cautious in attributing to naïve subjects (see Schütze [(1996)], chapter 3). However, to remain as faithful as possible to Dwyer and Pietroski's own exposition I use the term 'grammatical' throughout this discussion.

32 'Each other' is an anaphoric term, and so it must be bound by a local antecedent. There are two candidates for this role: 'John and Bill' and 'Mary'. 'Mary' — which is local with respect to 'each other' — is ruled out because of lack of number agreement, and 'John and Bill', which does agree with 'each other', is outside of its
} 
(vi) If in a sentence $S$ an anaphor is locally free, then $S$ is ungrammatical.

(vii) Therefore, (3) is ungrammatical.

Where (vii) = (i) and premises (iv)-(vi) designate Bloggs' implicit L-beliefs. Thus, if the speaker instantiated something like Argument 2, together with Argument 1, that would entail that notions such as BINDING and ANAPHOR are domain crossing, since they are recruited in a piece of reasoning leading to an extra-linguistic conclusion (iii). ${ }^{33}$

Nevertheless, I think that this picture fails to show that grammatical concepts have crossed domains, for two reasons:

(a) Accepting Bloggs' scenario as sufficient grounds for attributing something like Argument 2 to Bloggs would result in over-attribution of concepts.

(b) There is an alternative, plausible way of accounting for Bloggs' actions that does not postulate domain crossing, since it does not rely on ascribing Argument 2 to Bloggs.

\section{A) Over-attribution}

Consider this scenario, analogous to Dwyer and Pietroski's: an individual called Ploggs is watching an experiment. This one, like Bloggs', has two boxes, but the task is different, as it is a visual experiment. The generalization discovered by Ploggs is the following: whenever the experimenter shows the subject a circle, the left box contains ten dollars and the right box is empty, and when the experimenter produces a square the opposite obtains. The experimenter shows Ploggs the following figure and tells him to choose a box (see fig. 1):

Ploggs recognizes it as a square, and thus comes to believe that the money is in the right box. We can postulate that Ploggs' belief that the figure is a square is based on the information that it has edges, which finds in its turn a causal antecedent in the outputs of certain states that implement an algorithm for edge detection, based (say) on zero crossings. Since Ploggs' and Bloggs' examples are strictly parallel, we should be able to conclude the following: that the states of the early vision system contribute inferentially to other non-visual tasks, and in consequence, that the intervening concepts cross domains. This would in its turn lend support to the attribution of the concept of ZERO

local domain.

33 Higginbotham ([1987], p. 124-7) offers a group of related examples aimed at showing that linguistic knowledge is cognitive integrated. These focus on its role in the offline monitoring of speech and on general reasoning of language, including the repair of 'garden-path sentences'. My answer to Higginbotham's cases is along the same lines as my answer to Dwyer and Pietroski’s. 
CROSSING, for example, to Ploggs (who, by assumption, has never been exposed to vision science). But this conclusion is intuitively unacceptable. Furthermore, contents such as those of the early vision systems are the paradigm of subdoxastic, subpersonal states, which given their modular character are prevented from crossing domains (see Fodor, [1983]; Pylyshyn, [1999], Pylyshyn [2003]).

Thus Dwyer and Pietroski's interpretation of Bloggs' case would imply too liberal a view of concept attribution, since we could multiply parallel scenarios which, by parity of reasons, would allow us to attribute to individuals concepts that they clearly lack.

\section{B) An alternative picture}

The alternative picture is that whatever contents are handled by the visual faculty in the detection of edges (let us call them V-contents, in analogy to Dwyer and Pietroski's L-beliefs), they can only be directly engaged by early vision processes. States, such as beliefs, desires and intentions are directly involved in decision-making, and V-contents would form part of the causal chain leading to these states. However, the influence that V-contents exert on Ploggs' choice is not direct. Rather, V-states contribute to the output that the visual system (the product of a black box, as far as personal-level considerations are concerned), sends to the central systems involved in belief-fixation.

Analogously, Bloggs' scenario does nothing to discredit a corresponding view of the role of grammatical contents. In such a view, their direct influence extends to the linguistic domain exclusively, thus failing to cross domains. In consequence, their influence on central, personal level states is indirect, in their capacity as contributors to the outputs of the language faculty, which are then consumed by other areas of cognition (such as those leading to linguistic judgment). ${ }^{34}$

Considerations (A) and (B) together strongly suggest that Dwyer and Pietroski's argument fails to establish the crossing of domains for grammatical states.

\subsection{Objection: Concept talk is pleonastic}

Barber ([1996]) contains a criticism of arguments against linguistic belief—such as the argument I am proposing - that are based on lack of conceptual resources. He starts by laying out a plausible 'necessary and sufficient condition' for possession of a given concept $\mathrm{C}$, (A is any cognitive propositional attitude, $\mathrm{P}$ is a proposition, and $\mathrm{C}$ appears in $\mathrm{P})$ :

\footnotetext{
${ }^{34}$ In the end, however, the issue of what contents and processes are actually involved in acceptability judgments must be settled by appealing to empirical psychological research. For discussion see Devitt ([2006b]); Fitzgerald ([2009]); Culbertson and Gross ([2009]); and Schütze ([1996]), among others.
} 
(4) $S$ possesses $C$ is a necessary condition for $S A$ 's that $P$

But, as Barber observes, any claim of the form ' $\mathrm{p}$ is necessary for q' is equivalent to a claim of the form ' $\mathrm{q}$ is sufficient for p'. Thus, from (4) he gets (5), which is a sufficient condition for concept possession:

(5) $S A$ 's that $P$ is a sufficient condition for $S$ possesses $C$.

So, if we have reasons to attribute to a speaker the tacit belief that, in a given sentence, phrase $\mathrm{X}$ c-commands phrase $\mathrm{Y}$, then — given (5) —we have a (defeasible) reason for attributing the concept C-COMMAND to the speaker. Furthermore, to deny that the speaker has the belief in question, just on the claim that she does not possess C-COMMAND, would be question-begging. ${ }^{35}$ Thus,

(6) 'S believes that phrase X c-commands phrase Y'.

implies:

(7) 'S possesses the concept C-COMMAND', and the evidence (according to Barber) for (6) is at least as good the reasons against (7).

The Argument from Concept Possession is thus rendered ineffectual, because at most it forces a stalemate between the opponents.

There is a temptation to resist (5) by saying that having just one C-involving belief is not enough for the possession of concept C. ${ }^{36}$ The basis for this is the strong intuition that possession of $\mathrm{C}$ requires that $\mathrm{C}$ be deployed in a variety of beliefs (among other things; this was the point of singling out domain crossing as a key property). Barber replies that this does not contradict his thesis, since the need for more than one propositional attitude involving a concept in order to have even one is 'if true, a fact about propositional attitude attribution, not about concept possession' (Barber [1996], p. 58).

This answer is instructive, for it shows why Barber's argument is ineffective against premise 2. Barber's view entails the hypothetical claim that if $\mathrm{S}$ holds the belief that $\mathrm{P}$, then, ipso facto, $\mathrm{S}$ possesses the concept C. He also endorses the epistemic claim that if we have good reasons for attributing $\mathrm{P}$ to $\mathrm{S}$, then we automatically have good reasons to attribute $\mathrm{C}$ to $\mathrm{S}$. However, Barber's proposal is silent about the antecedent of the second (epistemic) conditional, namely, the categorical claim that we have good reasons to attribute $\mathrm{P}$ to $\mathrm{S}$. This is because Barber's theory does nothing to address the matter that is most pressing for us here: the evidential or epistemic issue of the conditions of attribution, which drove us in the first place to search for an empirically discriminative

\footnotetext{
${ }^{35}$ Barber ([1996], p. 57) writes:

$[\ldots]$ if we have a defeasible reason for thinking that an agent believes some proposition, then this reason cannot be defeated solely by the claim that the agent does not possess some concept involved in the allegedly believed proposition, because any reason for belief attribution is ipso facto a reason for concept possession ascription (italics mine).

36 Or more correctly, that having evidence for ascribing just one C-involving belief is not enough evidence for attributing concept C. I'll address this point shortly.
} 
criterion. ${ }^{37}$ So, even if we accept (4) and (5) as descriptive of the belief-concept relation, this does not preclude the possibility that the reasons for withholding attribution of grammatical beliefs (and thus grammatical concepts) will be on the whole weightier than the reasons for attributing them. In fact, this is what the argument for premise 2 shows, and if so, then the reasons for attributing CCOMMAND are defeated, and it is not question-begging to deny PAV on the basis of lack of concept possession.

\subsection{Conclusion}

This paper dealt with the cognitive relationship between speakers and their internal grammars, in the light of contemporary linguistic theory. It did so by stating and criticizing an initially attractive position on the nature of this relationship: the Propositional Attitude View (PAV). The particular objection against PAV explored here was the Argument from Concept Possession.

I focused on the second premise of Argument from Concept Possession, namely, that many competent speakers do not possess the concepts they should possess in order to believe the principles and rules of their grammars. To this end I proposed a criterion of concept possession, the goal of which was to help us settle disputes regarding concept possession. The criterion is based on a property of contents that I called 'domain crossing', and it postulates the capacity for crossing domains as a necessary condition for concept possession.

I then argued that grammatical concepts, such as C-COMMAND, fail the domain-crossing criterion in the case of naïe speakers. If this is correct, then typical speakers do not possess grammatical concepts, and so premise 2 of the Argument from Concept Possession is justified.

Consequently, PAV should be rejected: speakers do not literally 'know' or 'believe' the contents of their grammars.

Some comments on the scope of this conclusion: here I have discussed propositional attitudes toward the highly abstract generalizations and constraints posited by generative grammarians. There are other kinds of linguistic items, however, that are candidates to be implicitly believed by untutored speakers. Examples of these are that: (a) 'I went there yesterday' is acceptable in English whereas 'I yesterday went there' is not; (b) that in 'Bill suspects that John hates himself, 'John', but not 'Bill', can be the object of John's hatred; or (c) that 'Tonight Carla Bruni will talk about sex with Nicolas

\footnotetext{
${ }^{37}$ Barber's view is that talk about concepts is pleonastic, in the sense of being a linguistic epiphenomenon that emerges out of talk about beliefs. This clearly isn't the picture of beliefs and concepts that I am adopting here, where talk about concepts is not a mere epiphenomenon but deals with the actual constituents of the thoughts or propositions towards which thinkers have attitudes. In their role as components, they are invoked to explain crucial characteristics of thought, such as systematicity, as well as the inferential capabilities of individuals. The pleonastic theory, as Barber points out, is not incompatible with these phenomena, but it does nothing to advance of our understanding of them, either.
} 
Sarkozy' can be understood in more than one way, etc.

All of these constitute more or less superficial facts about particular sentences, which are available to speakers in general. But this does not detract from the overall significance of the conclusion, for my target was the rather more interesting (and controversial) claim that speakers' knowledge extends beyond these humdrum facts, to encompass the highly abstract principles of their grammars. 38

Other theories of grammar abandon the highly abstract, formal analyses that characterize work in the generative tradition, and so their generalizations do not advert to the syntactic concepts discussed here. ${ }^{39}$ Perhaps PAV would fare better if it were formulated in terms of these theories; however, here I have restricted myself to the most widely accepted theory, which is also the one most influential for philosophers.

The goals of this paper are mainly critical, or negative. Such goals are justified because progress can be achieved by ruling out attractive but inadequate views. That being said, I am aware that much remains to be done, such as spelling out the way in which a subpersonal psychological theory would account for the personal-level phenomena (such as linguistic judgments) that are usually cited as motivations for PAV, or determining the pertinence and implications of the analogy between linguistic theories and theories of vision. Indeed, we need a picture of how the speaker is related with her linguistic states, but these questions will have to be addressed in future work.

\section{Acknowledgements}

I would like to thank Tom McKay, Ishani Maitra, Jeff Glick, Jordan Dodd, Jaklin Kornfilt and David Braun for useful discussions of the material. I am particularly grateful to Michael Devitt and two anonymous reviewers, whose input led to significant improvements with respects to previous versions of the paper (though any mistake found here is of my own harvest).

\section{Philosophy Department}

Syracuse University

\footnotetext{
${ }^{38}$ It may also be that certain less abstract grammatical notions are within the speaker's purview, such as grammatical relations like 'subject' and 'object'. However, these are not notions that appear in the generalizations of the theories we are interested in, in part because they can be defined in terms of sentence structure; that is, they give way to more basic notions.

39 One example of this is Radical Construction Grammar (Croft [2001]), where the notion of construction (such as the passive, ditransitive, etc.) is taken to be basic.
} 
541 Hall of Languages

Syracuse, NY, 13244

USA

barrios.edison@gmail.com

\section{References}

Barber, A. [1998]: 'The Pleonasticity of Talk about Concepts', Philosophical Studies, 89, pp. 53-86.

Bermúdez, J. and Cahen, A. [2010]: 'Nonconceptual Mental Content', in E. Zalta (ed.) Stanford Encyclopedia of Philosophy, <plato.stanford.edu>.

Carey, S. [1985]: Conceptual Change in Childhood, Cambridge, MA: The MIT Press.

Chomsky, N. [1981]: Lectures on Government and Binding, Dordrecht: Foris.

Chomsky, N. [1986]: Knowledge of Language, New York: Praeger.

Clahsen, H. and Almazan, M. [1998]: 'Syntax and Morphology in Williams Syndrome', Cognition, 68, pp.167-98.

Collins, J. [2004]: 'Faculty Disputes', Mind and Language, 19, pp. 503-33.

Collins, J. [2006]: 'Between a rock and a hard place: a dialogue on the philosophy and methodology of generative linguistics', Croatian Journal of Philosophy, 6, pp. 471-505.

Collins, J. [2008]: ‘Knowledge of Language Redux', Croatian Journal of Philosophy, 22, pp. 3-43.

Crane, T. [1992]: 'The Nonconceptual Content of Experience', in T. Crane (ed), 1992, The Contents of Experience: Essays on Perception, Cambridge: Cambridge University Press.

Crimmins, M. [1992]: ‘Tacitness and Virtual Beliefs', Mind and Language, 7, pp. 240-63.

Croft, W. [2001]: Radical Construction Grammar: syntactic theory in typological perspective, Oxford: Oxford University Press.

Culbertson, J. and Gross, S. [2009]: 'Are linguists better subjects?', British Journal of Philosophy of Science, 60, pp. 721-736.

Davies, M. [1987]: 'Tacit Knowledge and Semantic Theory: can a five percent difference matter?', Mind, 96, pp. 441-62.

Davies, M. [1989]: 'Tacit Knowledge and Subdoxastic States', in A. George (ed.), 1989, Reflections on Chomsky. London: Blackwell. 
Davies, M. [2001]: 'Knowledge (Explicit and Implicit)', Philosophical Aspects. In N.J. Smelser and P.B. Baltes (eds), International Encyclopedia of the Social and Behavioral Sciences, Amsterdam: Elsevier Science Ltd., pp. 8126-32.

Dennett, D. [1969]: 'Content and Consciousness', London: Routledge.

Dennett, D. [1978]: Brainstorms, Cambridge, MA: The MIT Press.

De Sousa, R. [1971]: 'How to give a piece of your mind', Review of Metaphysics, 25, pp. 52-79.

Devitt, M. [2006a]: Ignorance of Language, Oxford: Oxford University Press.

Devitt, M. [2006b]: 'Intuitions in Linguistics', British Journal for the Philosophy of Science, 57, 481-513.

Devitt, M. [2006c]: 'Defending Ignorance of Language: Responses to the Dubrovnik Papers. Croatian Journal of Philosophy', 6, pp. 571-606.

Dienes, Z. and Perner, J. [1999]: 'A Theory of Implicit and Explicit Knowledge', Behavioral And Brain Sciences, 22, pp. 735-808.

Dwyer, S. and Pietroski, P. [1996]: 'Believing in Language', Philosopby of Science, 63, 338-73.

Evans, G. [1981]: 'Semantic Theory and Tacit Knowledge', in C. Holzmann and C. Leich (eds.), 1981, Wittgenstein: To Follow a Rule. London: Routledge.

Evans, G. [1982]: The Varieties of Reference, Oxford: Oxford University Press.

Field, H. [1978]: 'Mental Representation', Erkenntnis, 13, pp. 9-18.

Fitzgerald, G. [2009]: 'Linguistic Intuitions', British Journal for the Philosophy of Science, 61, pp. 1-38.

Fodor, J. [1968]: 'The Appeal to Tacit Knowledge in Psychological Explanation', The Journal of Philosophy, 65, 627-640.

Fodor, J. [1983]: The Modularity of Mind, Cambridge, Mass: The MIT Press.

Fodor, J. [1998]: Concepts: Where Cognitive Science Went Wrong, Oxford: Oxford University Press.

Fodor, J. and Pylyshyn, Z. [1988]: 'Connectionism and Cognitive Architecture: A Critical Analysis', in S. Pinker and J. Mehler (eds.), Connections and Symbols, Cambridge, Massachusetts: MIT Press.

Gelman, R. [1990]: 'First principles organize attention to and learning about relevant data: Number and the animate-inanimate distinction as examples', Cognitive Science, 14, pp. 79-106.

Gelman, S. A., and Opfer, J. [2002]: 'Development of the Animate-Inanimate Distinction', in U. Goswami, U. (ed.), 2002, Blackwell Handbook of Childhood Cognitive Development, Malden, MA: Blackwell.

Gentner, D. [1983]: Structure-mapping: A theoretical framework for analogy, Cognitive Science, 7, pp. 155-170. 
Gottfried, G. M. [1997]: ‘Comprehending compounds: Evidence for metaphoric skill?’, Journal of Child Language, 24, pp.163-186.

Graves, C., Katz, J.J., Nishiyama, Y., Soames, S., Stecker, R. and Tovey, P. [1973]: 'Tacit Knowledge', Journal of Philosophy, 70, pp. 318-30.

Gutheil, G., Vera, A. and Keil, F.C. [1998]: 'Do houseflies think? Patterns of induction and biological beliefs in development', Cognition, 66, pp. 33-49.

Higginbotham, J. [1998]: ‘Conceptual competence’, Philosophical Issues, 9, pp. 149-162.

Hoffman, D. [1998]: Visual Intelligence: How We Create What We See, New York: Norton and Co.

Isac, D. and Reiss, C. [2008]: I-Language: An Introduction to Linguistics as Cognitive Science, Oxford: Oxford University Press.

Keil, F. [1979]: Semantic and conceptual development: An ontological perspective, Cambridge, MA: MIT Press.

Keil, F. [1992]: 'The Origins of an Autonomous Biology', in M. Gunnar and M. Maratsos (Eds.), 1992, Modularity and Constraints in Language and Cognition: The Minnesota Symposia, Hilldale, N.J.:

Earlbaum.

Knowles, J. [2000]: 'Knowledge of Grammar as a Propositional Attitude', Philosophical Psychology, 13, pp. 325-53.

Larson, R.K. and G. Segal [1995]: Knowledge of Meaning: An Introduction to Semantics, Cambridge, Mass: The MIT Press.

Lycan, W. [1986]: 'Tacit Belief', in R. Bogdan (ed.), 1986, Belief: Form, Content, and Function, Oxford, UK: Oxford University Press.

Maloney, J.C. [1990]: 'It's hard to believe', Mind and Language, 5, pp. 122-48.

Marr, D. [1982]: Vision, San Francisco, CA: W.H. Freeman and Co.

Matthews, R. [2006]: 'Could Competent Speakers Really Be Ignorant of Their Language?', Croatian Journal of Philosophy, 6, pp. 459-69.

McLeod, P. and Dienes, Z. [1996]: 'Do fielders know where to go to catch the ball, or only how to get there?', Journal of Experimental Psychology: Human Perception and Performance, 22, pp. 531-543.

Nagel, T. [1969]: 'Linguistics and Epistemology', in S. Hook (ed.), 1969, Language and Philosophy, New York University Press, pp. 171-181.

Opfer, J. E., \& Siegler, R. S. [2004]: 'Revisiting preschooler's living things concept: A microgenetic analysis of conceptual change in basic biology', Cognitive Psychology, 49, pp. 301 - 332.

Peacocke, C. [1986]: 'Explanation in Computational Psychology: Language, Perception and Level 1.5, Mind and Language, 1, pp. 101-23.

Peacocke, C. [1992]: A Study of Concepts. Cambridge, MA: The MIT Press. 
Peacocke, C. [1998]: 'Implicit Conceptions, Understanding and Rationality', Philosophical Issues, 9, pp. 43-88.

Poulin-Dubois, D., Lepage, A., \& Ferland, D. [1996]: 'Infants' concept of animacy', Cognitive

Development, 11, pp. 19-36.

Pylyshyn, Z. [1984]: Computation and Cognition, Cambridge, MA: The MIT Press.

Pylyshyn, Z. [1999]: 'Is vision continuous with cognition? The case for cognitive impenetrability of visual perception', Behavioral and Brain Sciences, 22, pp. 341-423.

Pylyshyn, Z. [2003]: Seeing and Visualizing, Cambridge, MA: The MIT Press.

Rakison, D. and Poulin-Dubois, D. [2001]: 'Developmental Origin of the Animate-inanimate Distinction', Psychological Bulletin, 429, pp. 209-228.

Rey, G. [2003a]: 'Intentional Content and a Chomskian Linguistics', in A. Barber (ed.), 2003, Epistemology of Language, Oxford: Oxford University Press, pp. 140-186.

Rey. G. [2003b]: 'Chomsky, Intentionality and a CRTT', in L. Antony, and N. Hornstein (eds.), Chomsky and his Critics. Oxford: Blackwell.

Schacter, D. [1996]: Searching for Memory, New York: Basic Books.

Schiffer, S. [1998]: ‘Doubts about Implicit Conceptions’, Philosophical Issues, 9, pp. 89-91.

Schütze, C. [1996]: The Empirical Base of Linguistics: Grammaticality Judgments and Linguistic Methodology, Chicago: Chicago University Press.

Smith, B. [2006a]: 'What I Know When I Know a Language', in E. Lepore and B. Smith (eds.), The Oxford Handbook of Philosophy of Language. Oxford: Oxford University Press.

Smith, B. [2006b]: 'Why We Still Need Knowledge of Language' Croatian Journal of Philosophy, 6, pp. 431-57.

Shutts, K., Markson, L., \& Spelke, E. [2009] 'The developmental origins of animal and artifact concepts', in B. Hood and L. Santos (eds.), The Origins of Object Knowledge, pp. 189-210, Oxford: Oxford University Press.

Smith. N. and Tsimpli, I. [1995]: The Mind of a Savant: Language Learning and Modularity, London: Blackwell.

Stich, S. [1978]: 'Beliefs and Subdoxastic States', Pbilosophy of Science, 45, pp. 499-518

Wright, C. [1986]: ‘Theories of Meaning and Speaker's Knowledge’, in C. Wright, 1986, Realism, Meaning and Trutb: Oxford: Blackwell.

Zukoswski, A. [2009]: 'Adolescents with Williams Syndrome Know the Locality Requirement for Reflexives’, [Unpublished]. 
